\title{
O lugar do desenho na metodologia aplicada às Ciências Humanas: uma alternativa de como narrar pesquisas etnográficas
}

\author{
El lugar del diseño en la metodología aplicada a las Ciencias Humanas: \\ una alternativa de cómo narrar investigaciones etnográficas
The place of drawing in the methodology applied to the Human Sciences: an alternative of how to narrate ethnographic researches

\author{
Tanize Machado Garcia ${ }^{1}$
}

Guilherme Rodrigues de Rodrigues ${ }^{2}$

\begin{abstract}
Resumo
Como narrar? Essa é uma questão perseguida por pesquisadoras (es) na hora de escreverem suas etnografias. Dar conta de gestos, sensações, aromas, sabores, cores, relações e tantos outros detalhes são desafios a serem enfrentados. A tendência atual de retomar o desenho como elemento da produção de dados empíricos, na contemporaneidade, evidencia o potencial de aprofundamento de contextos e abstrações do campo. Neste trabalho propomos contemplar o desenho como método pertinente na pesquisa antropológica, valendo-se tanto do processo de desenhar quanto do próprio produto em si. Um dos recortes desse trabalho resulta da pesquisa etnográfica de mestrado em Antropologia Social e Cultural (UFPel) da autora, tendo como tema as dinâmicas sociais no Mercado Público de Pelotas (RS), após a política pública de intervenção municipal em parceria com o IPHAN, para a requalificação do prédio e entorno que ocorreu entre 2009 e 2012. O outro recorte que trazemos aqui resulta da etnografia realizada pelo autor para a conclusão de curso do Bacharelado em Antropologia (UFPel), na qual discute sobre o cotidiano de pessoas com deficiência visual na cidade, tendo em vista todos os problemas históricos de não acessibilidade desencadeados pelas concepções de meio urbano daqueles que tem visão. Assim, apresentamos o desenho, através da antropologia visual, como método e recurso narrativo para a pesquisa em ciências humanas.
\end{abstract}

Palavras-Chave: desenho; antropologia-visual; método-etnográfico; mercado-público-Pelotas; CRV-LouisBraille

\section{Resumen}

¿Cómo narrar? Esta es una cuestión perseguida por investigadoras (es) em el momento de escribir sus etnografías. Dar cuenta de gestos, sensaciones, olores, sabores, colores, relaciones y tantos otros detalles son desafíos a enfrentarse. La tendencia actual de reanudar el diseño como elemento de la producción de datos empíricos, en la contemporaneidad, evidencia el potencial de profundización de contextos y abstracciones del campo. En este trabajo proponemos contemplar el diseño como método relevante en la investigación antropológica, valiéndose tanto del proceso de dibujar cuanto del propio producto etnográfico. Una de las obras de este trabajo resulta de la investigación etnográfica de maestría en Antropología Social y Cultural (UFPel) de la autora, teniendo como tema las dinámicas sociales en el Mercado Público de Pelotas (RS), después de la política pública de intervención municipal en asociación con el IPHAN, para la recalificación del edificio y entorno que ocurrió entre 2009 y 2012. El otro recorte que traemos aquí resulta de la etnografía realizada por el autor para la conclusión de curso del Bachillerato en Antropología (UFPel), en la que discute sobre el cotidiano de personas con discapacidad visual en la ciudad, teniendo en vista todos los problemas históricos de no accesibilidad desencadenados por las concepciones de medio urbano de aquellos que tienen visión. Así,

\footnotetext{
${ }^{1}$ Mestre em Estudos Culturais, UFPEL; nize.garcia@gmail.com

${ }^{2}$ Bacharel em Antropologia, Mestrando no Programa de Pós-Graduação em Antropologia (PPGAnt/UFPel); Pelotas, Rio Grande do Sul, Brasil; guilhermerdr.rodrigues@gmail.com
} 
presentamos el diseño, a través de la antropología visual, como método y recurso narrativo para la investigación en las ciencias humanas.

Palabras claves: Diseño; Antropología visual; Método-etnográfico; Mercado-Público-Pelotas; CRV-LouisBraille

\begin{abstract}
How to narrate? This is a question pursued by researchers (s) at the time of writing their ethnographies. Giving attention to gestures, sensations, smells, flavors, colors, relationships and so many other details are challenges to be faced. The current tendency to resume drawing as an element of the production of empirical data, in contemporaneity, evidences the potential of deepening contexts and abstractions about field observations. In this work we propose to propose drawing as a relevant method in anthropological research, using both, the drawing process and the product itself. One of the cuttings of this work results from the author's ethnographic research in Social and Cultural Anthropology (UFPel), having as its theme the social dynamics in the Public Market of Pelotas (RS), after the public policy of municipal intervention in partnership with IPHAN, for the requalification of the building and surroundings that took place, between 2009 and 2012. The other clipping that we bring here results from the ethnography realized by the author for the conclusion of the course of the Bachelor of Anthropology (UFPel), in which he discusses about the daily life of people with visual impairment in the city, in view of all the historical problems of non-accessibility triggered by urban conceptions of those who see well. Thus, we present the design, through visual anthropology, as a method and narrative resource for research in human sciences.
\end{abstract}

Keywords: Drawing; Visual-anthropology; Ethnographic-method; Public-Market-Pelotas; CRV-Louis-Braille.

\title{
1. Introdução
}

O cerne da produção epistemológica prevê uma série de procedimentos para produção de dados, análise e apresentação dos resultados em coerência com um arcabouço teórico que os tornem qualificáveis e/ou quantificáveis. A partir das pesquisas realizadas por cientistas nas mais variadas áreas do conhecimento e níveis de graduações, muitos desses conjuntos de métodos são notadamente eficazes em termos da retomada e apresentação das experiências realizadas. As pesquisas resultam, via de regra, em textos pasteurizados que publicamos em dissertações, teses, periódicos, etc., com o predomínio da palavra escrita e de figuras ilustrativas.

Para Caiuby (1993), a partir da terceira década do século XX teve início um movimento de diálogo que, articulando diferentes áreas do conhecimento nas humanidades, passaram a dar foco às instâncias subjetivas para compreensão do "[...] comportamento humano [...] de práticas sócio-culturais ou comportamento individual [...]” (1993, p. 47).

Nas humanidades, mais precisamente na antropologia, dedicamos grande parte dos tempos de nossas formações, discutindo os formatos utilizados para darmos conta da complexidade de nossas experiências, a fim de expormos com eficiência o resultado de nossos mergulhos nas águas profundas de sistemas de relações sociais distintos. Em face das múltiplas visões de mundo que coexistem na colcha social, teorias são articuladas e novas ferramentas são incorporadas no processo de construção do pensamento sobre nossos 
universos de observação. Numa revisão sobre o amadurecimento da disciplina, Caiuby (1993) já expõe o caráter da transformação na produção antropológica.

[...] conceitos científicos, não são perenes e imutáveis; embora cada um deles tenha, na disciplina que o elaborou, uma trajetória específica, foram elaborados numa época determinada, assimilados por outras disciplinas, reformulados. São também conceitos que, construídos a partir de dados vindos da observação do comportamento, devem ser associados aos procedimentos específicos utilizados na sua coleta e, obviamente, dentro do quadro teórico de que fazem parte, (CAIUBY, 1993, p. 49).

Assim, nesse trabalho, consideramos a abordagem de nossos universos de pesquisa com o uso do "desenho etnográfico" como um tipo de desenho que foge da ideia da ilustração (AZEVEDO, 2016b, p. 2), outrossim, é uma forma de abstração dos espaços, de treinar nosso olhar, baseados nas experiências e em nossas relações com nossos interlocutores. Logo, a utilização do diário gráfico como inscrição pertinente dos dados coletados no trabalho de campo, foi somado ao produto final de nossas análises o que resultou e deu forma a uma etnografia de características visuais, se comportando como narrativa científica e poética. Uma forma de escrever para além do uso do verbo.

Também levamos em conta a transformação das dimensões relacionais humanas, concordando, portanto que a criatividade para a conjuração de uma etnografia perpassa o entendimento de que o modo como os dados foram produzidos, seus meios, relações empíricas e procedimentos de inscrição em nossos diários de campo, são fundamentais para a construção de sentido da narrativa etnográfica como produto teórico-científico. De acordo com a provocação de Peirano (2014) a etnografia não é um método, mas um procedimento com implicações teóricas profundas, um meio de sofisticação epistemológica na antropologia. Dessa forma, a criatividade é um componente fundamental de suas construções, pois, assim como a teoria científica e a literatura influenciam nossas características de escrita, a digital de cada pesquisador, com suas inclinações (talentos), sempre se deixam a ver de alguma forma. A produção etnográfica incorre em rearranjos do arcabouço teórico que fundamentam a empiria.

$\mathrm{Na}$ intenção de somar outras perspectivas e ferramentas para as contribuições e discussões no que diz respeito ao fazer epistemológico, centrados na metodologia de pesquisa, compartilhamos os resultados visuais de nossas etnografias, com base em nossas pesquisas de pós-graduação e graduação no curso de Antropologia da Universidade Federal de Pelotas (UFPel-RS). O primeiro trabalho a ser apresentado resulta da pesquisa etnográfica de mestrado em Antropologia Social e Cultural (UFPel): Mercado Público de Pelotas no País das Maravilhas: uma etnografia sobre a pluralidade narrativa de um patrimônio em disputa 
(GARCIA, 2018), tendo como tema as dinâmicas sociais no Mercado Público de Pelotas (RS), após a política pública de intervenção municipal em parceria com o IPHAN, para a requalificação do prédio e entorno, o que ocorreu entre 2009 e 2012. No segundo recorte trazemos a etnografia: Antropologia em ação: etnografia sobre o Centro de Reabilitação Visual Louis Braille em Pelotas-RS (RODRIGUES, 2018), um trabalho de conclusão de curso do Bacharelado em Antropologia (UFPel), no qual se discutem questões sobre o cotidiano de pessoas com deficiência visual na cidade, considerando, para isso, os problemas históricos de não acessibilidade urbana, desencadeados pelas concepções de cidade elaboradas por pessoas sem deficiência. Ou seja, a problemática da acessibilidade foi pensada e exposta nesta pesquisa em interlocução com quem tem baixa visão ou cegueira. Por consequência, os desenhos com tendências surrealistas exacerbam os contrastes de viver numa cidade cujos limites são demarcados pelos seus próprios desafios. Dessa forma, a provocação consiste em desenhar o que é visto por outros sentidos de corpo.

É importante frisar que estes produtos etnográficos são frutos de discussões, experimentos e oficinas para o desenvolvimento de outras formas de narrar o espaço urbano da cidade e, para isso, contamos com a orientação da Professora Cláudia Turra Magni, mas também na parceria de outros docentes e discentes que contribuíram como colaboradores ímpares nessa jornada e sem os quais a potência do desenho nem viria a um mundo aparentemente concreto. É o caso, por exemplo, da participação da professora de Artes Visuais, Vivian Herzog, da Universidade Federal de Pelotas, ministrante de oficinas de desenho no grupo de pesquisa Antropoéticas, vinculado ao Laboratório de Ensino, Pesquisa e Produção em Antropologia da Imagem e do Som (LEPPAIS), no ano de 2017. Nesse caminho, a partir de uma série de experimentações que haviam começado em 2016, fomos iniciados com breves exercícios de desenhos dos nossos objetos de pesquisa, e do próprio ambiente de encontros para discussões do grupo, onde nos reuníamos para as conversas, culminando com as oficinas citadas. Nessas oportunidades, fomos apresentados aos diferentes materiais que poderíamos utilizar em campo e tivemos a possibilidade de nos conhecermos, assim como de darmos vazão a outras possibilidades de olhar, despertando nossas habilidades de desenhadores, ação adormecida na infância. Fomos, aos poucos, nos reencontrando com nossos traços e nos desafiando, pelo encorajamento e apoio de nossos pares, desinibimos outros sentidos na troca da escrita pelo desenho. Foi a partir daí que nossas pesquisas tomaram rumos que até então não havíamos imaginado.

Sobre essa questão, também pensamos sobre a transformação no processo de construção metodológica que levou a cabo a escrita e a inscrição etnográfica. Assim, 
articulamos o tradicional diário de campo ao diário gráfico, onde condensávamos nossos desenhos, esboços dos campos, descrições e abstrações sobre eles. Tanto a manutenção das formas mais tradicionais de escrita, quando a corajosa inserção de nossos desenhos demonstram outra forma de contribuir para o fazer antropológico, defendidos no ano de 2018.

Como desafio da produção visual, o artigo que apresentamos também discorrerá, de forma sucinta a mesma construção. $O$ verbo não repete o que diz a imagem, mas se complementam, uma vez que não pretendemos que nossos desenhos se mostrem como ilustrações a reboque do texto, mas sim, são colocados como grafia, como narrativa científica das experiências que vivemos. Os desenhos, dessa maneira, são elementos provocativos, desenhos críticos que permitem convidar, a qualquer tempo, também, a participação ativa do leitor com a bagagem de suas experiências no processo de compreensão e abstração do que foi sendo narrado.

\section{O Mercado Público de Pelotas (RS): narrativas de um lugar em transformação}

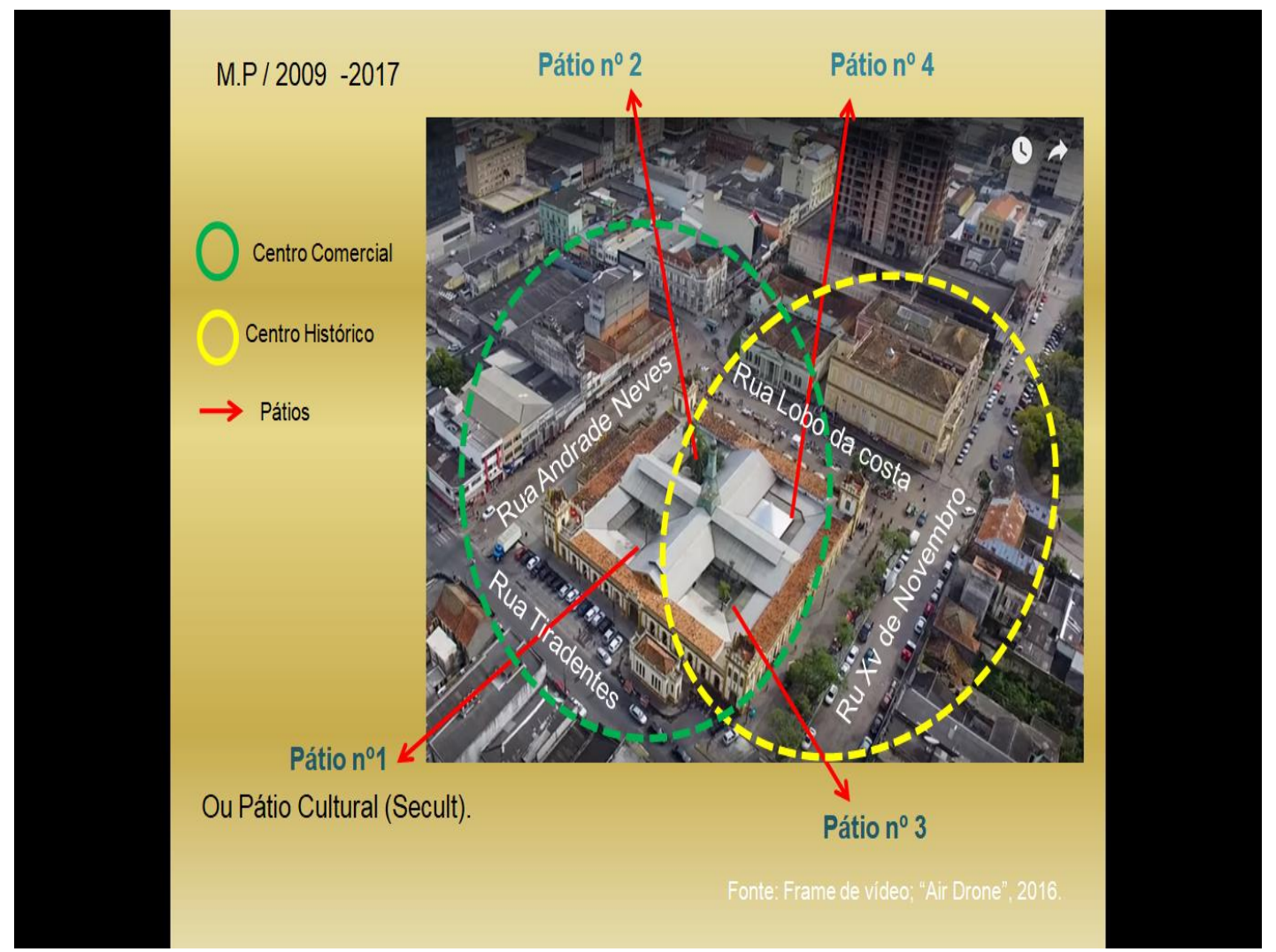

Figura 1: Localização Espacial do Mercado Público de Pelotas em relação ao centro comercial e o centro histórico. Fonte: GARCIA, 2018.

O Mercado Público de Pelotas construído no final do século XIX. Corresponde a um processo de construção de cidade baseado nos moldes de urbanização influenciado pelos meios de produção das charqueadas, estâncias de criação de gado de corte, onde a carne era 
salgada e seca ao sol e, posteriormente, exportada para o norte do Brasil. No contexto, a mão de obra dessas fazendas era mantido por negros escravizados cuja representatividade nas narrativas oficiais não cessa em se encerrar na esfera do trabalho. A cultura africana pouco ou nada é mencionada. O charque era, assim, produzido pelos escravos e servia para alimentá-los em outras regiões do país. Com a opulência econômica gerada pela indústria do charque, casarões, teatros, biblioteca pública, uma praça e toda uma forma de vida de requinte se desenvolveram na região do centro da cidade denominada, atualmente, como centro histórico.

As reminiscências do modo de vida da época permanece em exemplares arquitetônicos que foram inventariados e tombados no centro da cidade de Pelotas, compondo uma narrativa do passado, no presente. Essas narrativas oficiais servem ao propósito de contar que cidade é esta, tendo no desenvolvimento da atividade turística na região seu foco, nos dias de hoje. $\mathrm{O}$ Mercado Público foi patrimonializado pelo tombamento municipal no ano de 1985 e passou, entre os anos de 2009 até 2012, pelo processo de reforma, realizado através da parceria entre a Secretaria de Cultura (Secult) do município e o Instituto do Patrimônio Histórico e Artístico Nacional (IPHAN).

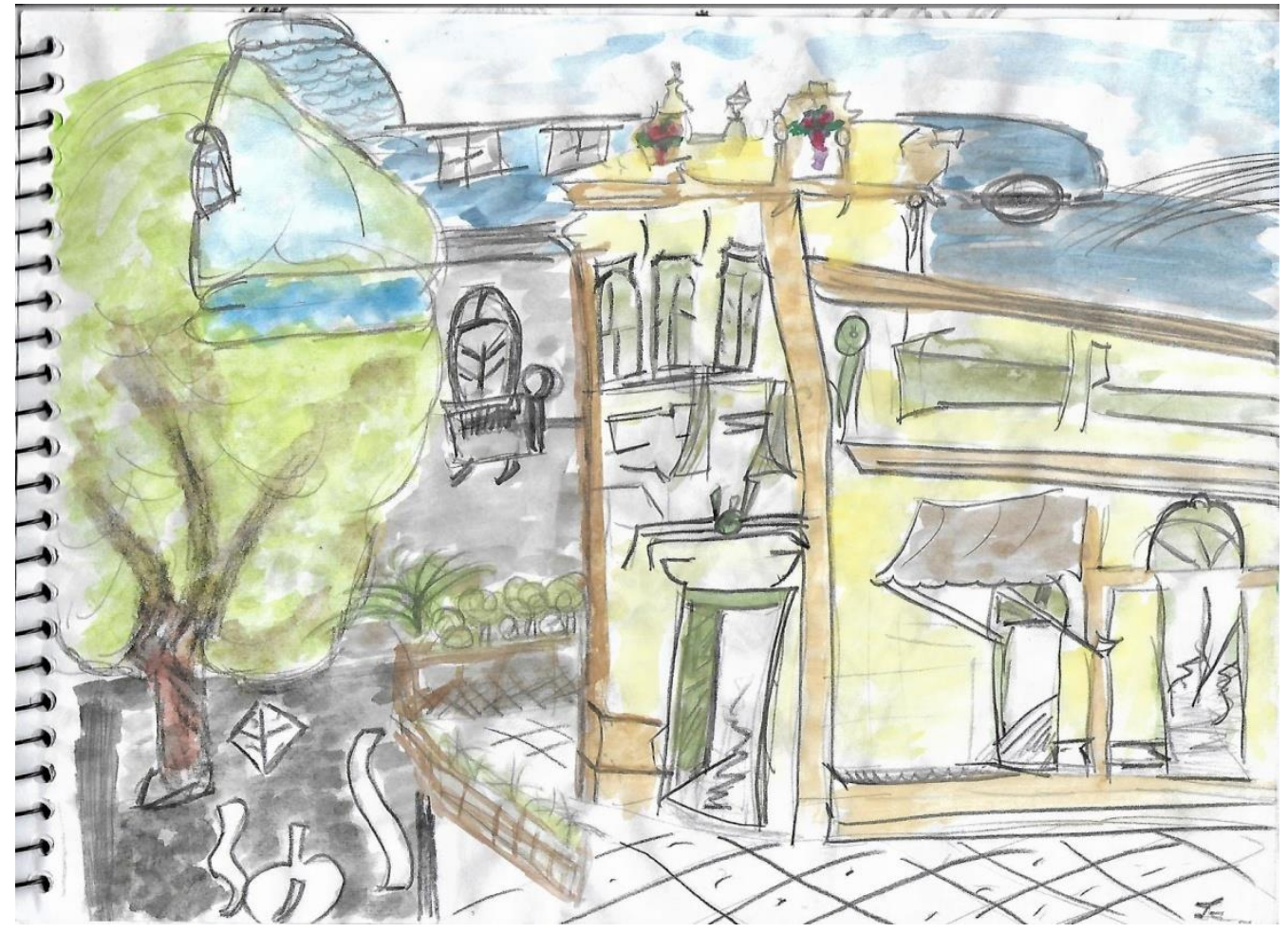

Figura 2: Aquarela. Mercado Público de Pelotas (RS). Uma narrativa do passado no presente. Fonte: GARCIA, 2018.

A partir de materiais produzidos na intenção de contar narrativas atrativas para incentivar o aumento no número de turistas, imagens como a de um negro puxando a nado uma pelota, tipo de embarcação que teria originado o nome da cidade, levando um homem 
branco com uma criança nos braços, o desenho evidencia a força de trabalho e alude as posições sociais que cada um dos grupos assume dentro da narrativa oficial.

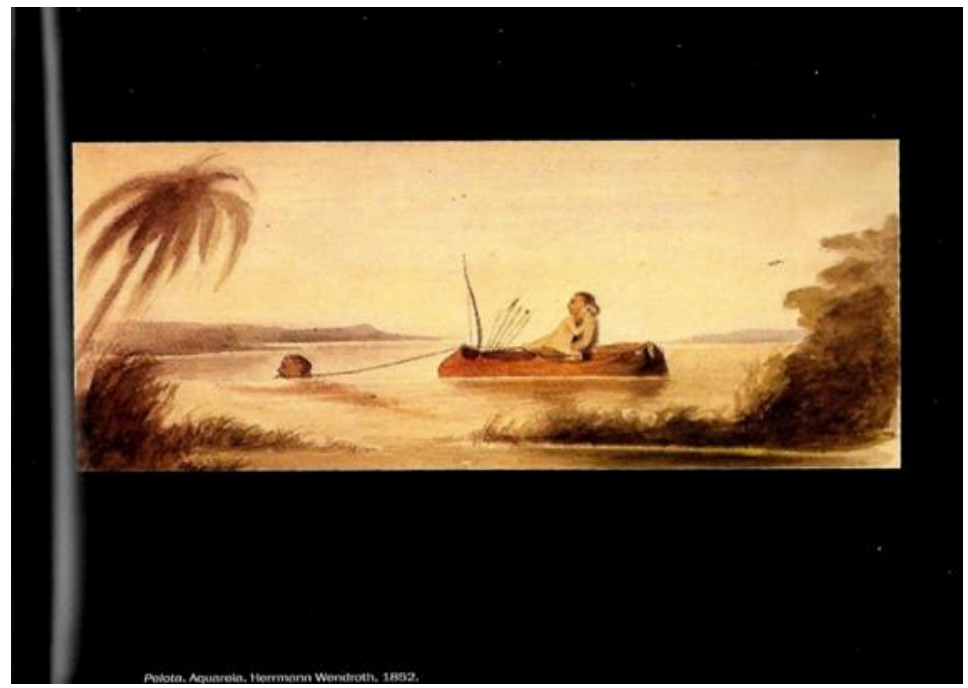

Figura 3: "Pelota". Aquarela. Herrmman Wendrorth, 1852. Material distribuído pelo SEBRAE/RS em evento para o desenvolvimento do turismo. Fonte: CUSTÓDIO, 2009, p. 96.

Anterior ao período denominado como requalificação patrimonial, um processo trata de intervenções em lugares de patrimônio tidas como obsoletas, mas impregnadas de conteúdos simbólicos, como os centros históricos, com o objetivo de atender a um planejamento urbano pontual e estratégico $\left(\operatorname{IPHAN}^{3}\right)$. Em Pelotas, esse procedimento ocasionou o fechamento do Mercado Público e a transformação do local em termos de estrutura e prestação de serviços. De um local onde predominantemente havia lojas de venda de artigos de baixo valor econômico, lanchonetes, barbearias, peixarias, calçados, animais, etc.; passou a contar com um ambiente setorizado, de alimentos e bebidas, carnes, artesanato, restaurantes, intensa agenda de atrações musicais, entre outros que, mesmo conservando negociações entre o poder público e os frequentadores, ainda se percebia pelas narrativas e evidências empíricas as tentativas de barrar eventos musicais das periferias. De negar a presença da prostituição e da violência num lugar reconfigurado para a prática do lazer e do turismo na cidade.

A partir dos desenhos produzidos no período empírico da pesquisa, foi possível perceber como o mesmo lugar é vivido e narrado por diferentes atores e grupos sociais. A partir de diferentes perspectivas sobre o Mercado Público, notava-se que as narrativas sobre o local o transformavam em versões diferentes dele mesmo, assim como as narrativas particulares alçavam no passado histórico das narrativas oficiais elementos que eram

\footnotetext{
${ }^{3}$ Fonte: http://portal.iphan.gov.br/dicionarioPatrimonioCultural/detalhes/58/revitalizacao.
} 
atravessados pelas experiências de frequentadores e trabalhadores que faziam parte do cotidiano do local. Dessa forma, o Mercado era acomodado em contextos históricos diferentes dos que se via na veiculação de mensagens institucionais do patrimônio arquitetônico material e imaterial da cidade. Esses interlocutores tiveram suas identidades preservadas pela antropóloga, dado o cenário de constantes disputas das quais era alvo no período da pesquisa. O processo de construção do cotidiano, assim como da composição de narrativas é entendido a partir do conceito de invenção que, segundo Wagner (2010) é uma condição maleável decorrente das tentativas de explicarmos em relação as interações sociais. Sendo relacional, até mesmo a criatividade do antropólogo é dependente da criação dos interlocutores, expressa pela fatal, escrita, fotografia e desenho, a invenção ou a criatividade não pode ser mencionada na esfera do julgamento entre verdade ou mentira, mas sim como uma forma de exposição de subjetividades e que expõem diferentes formas de ver e viver o meio.

Atualmente, o Mercado é um local que recebe grande número de turistas. O que se segue, é uma narrativa visual que expõe diferentes versões do local atuante e difuso, pois que delineia diferentes margens de relação entre centro e periferia, entre passado e presente, entre o turismo receptivo e as práticas de lazer e trabalho de citadinos no centro da cidade de Pelotas.

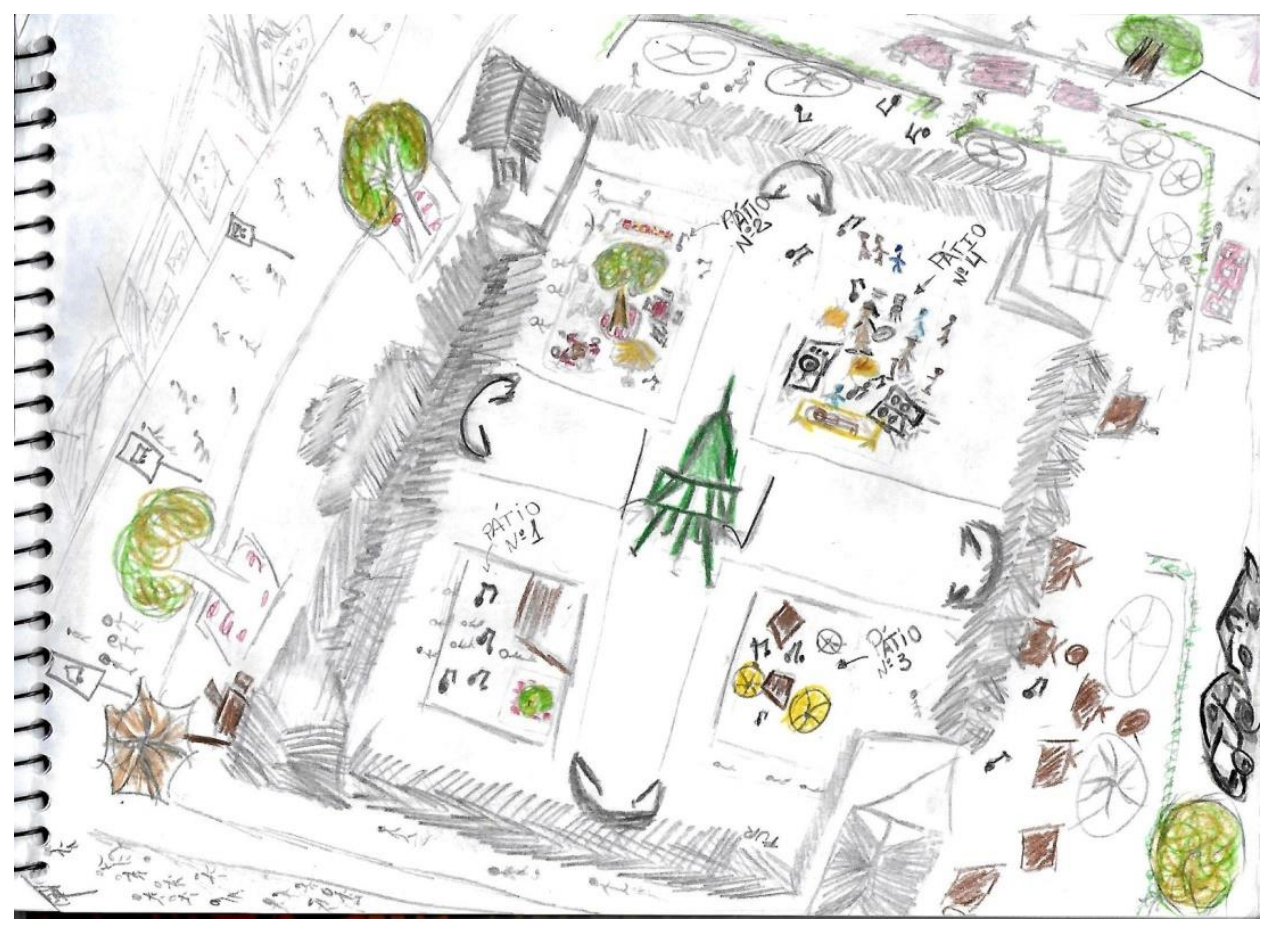


RELACult - Revista Latino-Americana de Estudos em Cultura e Sociedade

Revista Latinoamericana de Estudios en Cultura y Sociedad | Latin American Journal of Studies in Culture and Society V. 05, ed. especial, abr., 2019, artigo n ${ }^{\circ} 1381$ | claec.org/relacult |e-ISSN: 2525-7870
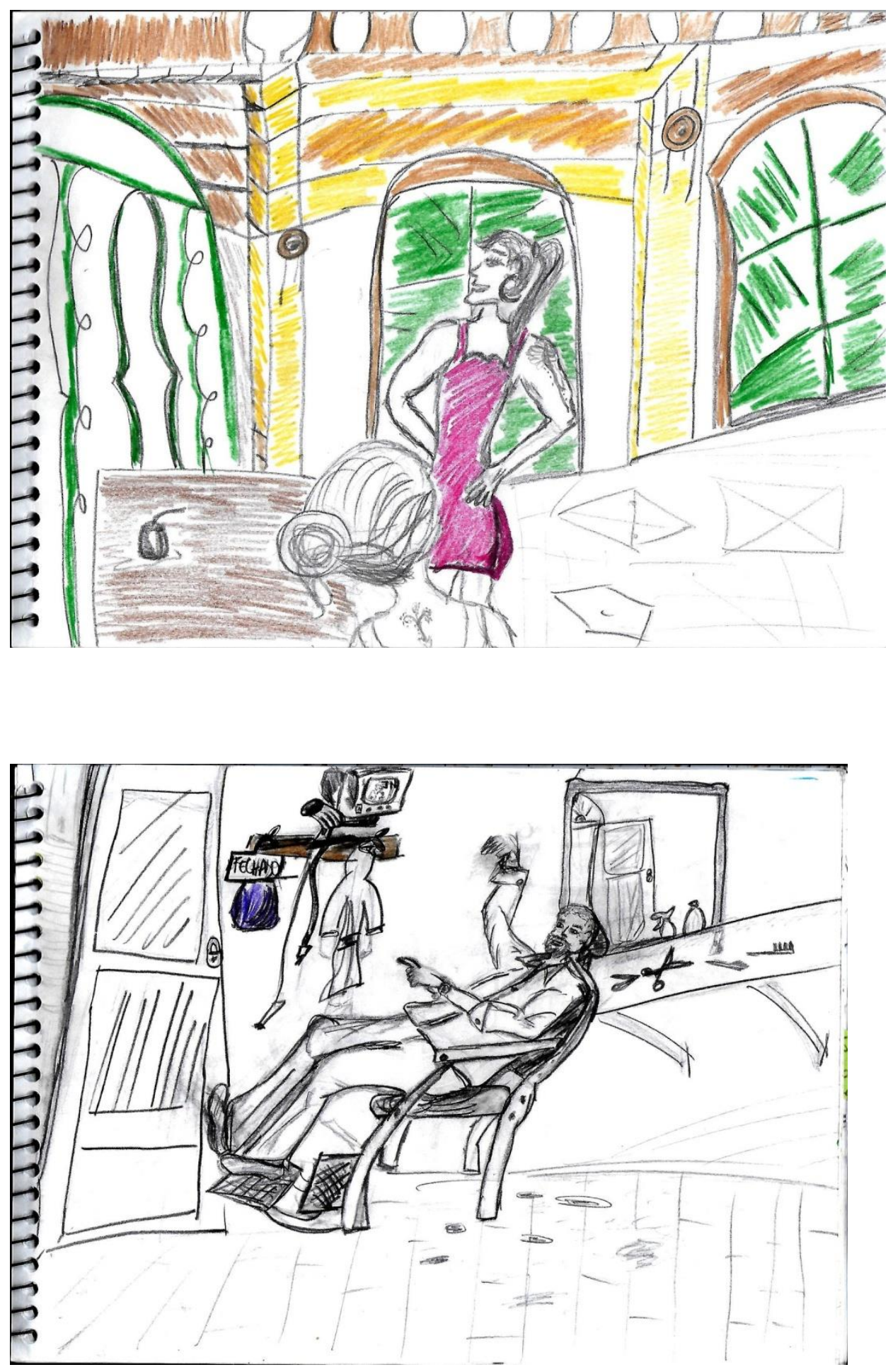
RELACult - Revista Latino-Americana de Estudos em Cultura e Sociedade

Revista Latinoamericana de Estudios en Cultura y Sociedad | Latin American Journal of Studies in Culture and Society V. 05, ed. especial, abr., 2019, artigo no 1381 | claec.org/relacult | e-ISSN: 2525-7870
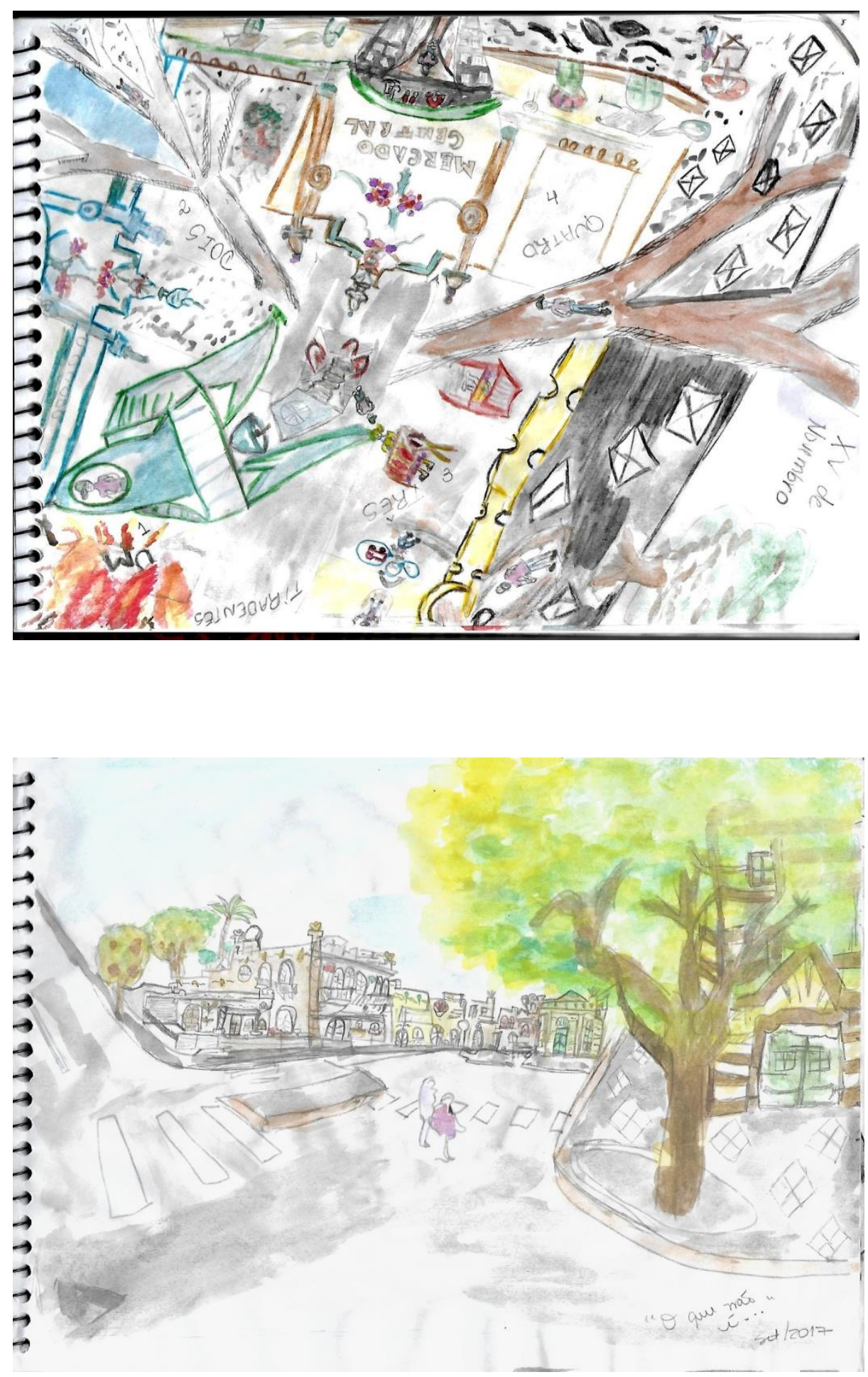
RELACult - Revista Latino-Americana de Estudos em Cultura e Sociedade

Revista Latinoamericana de Estudios en Cultura y Sociedad | Latin American Journal of Studies in Culture and Society V. 05, ed. especial, abr., 2019, artigo n ${ }^{\circ} 1381$ | claec.org/relacult |e-ISSN: 2525-7870
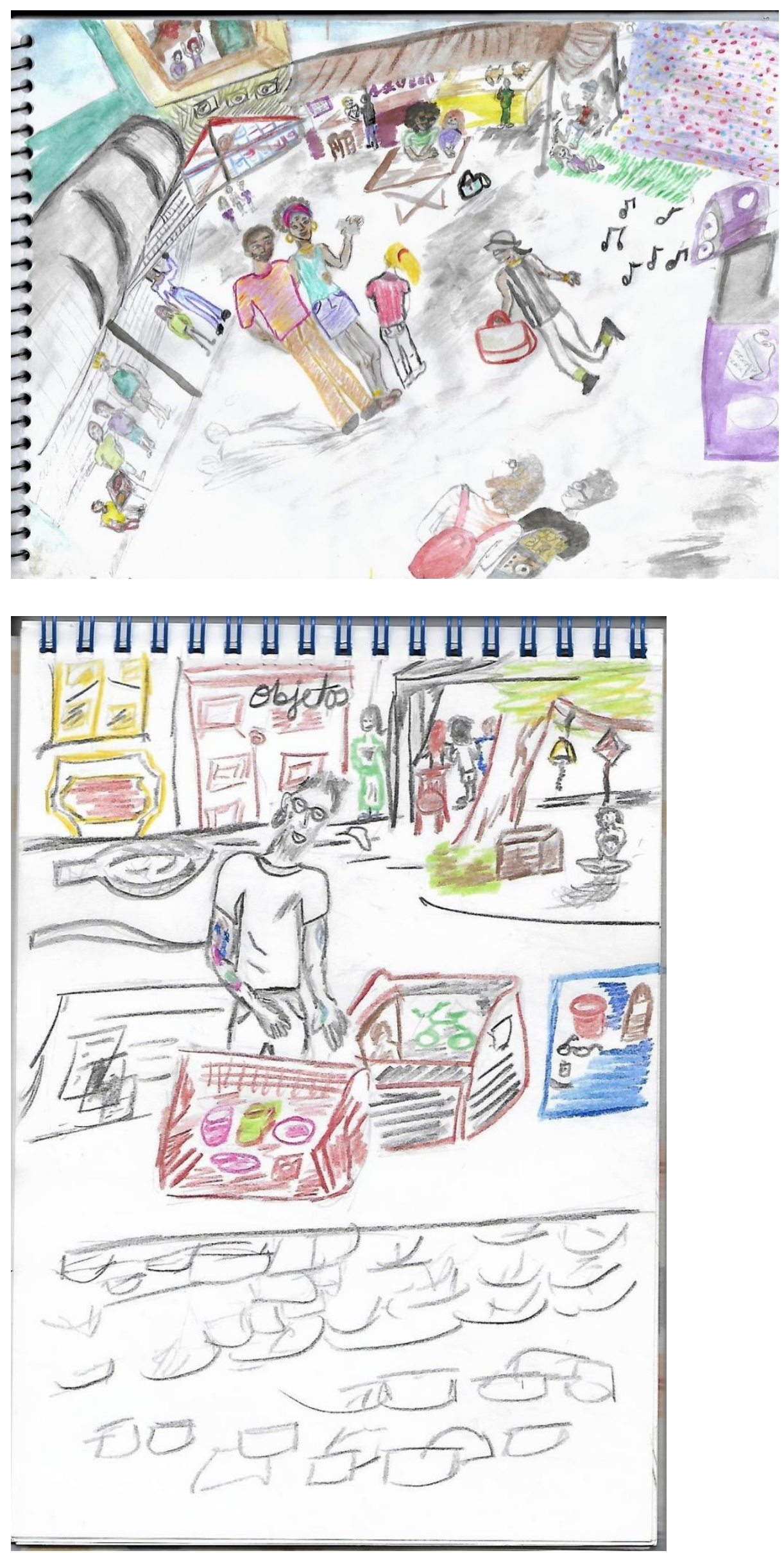


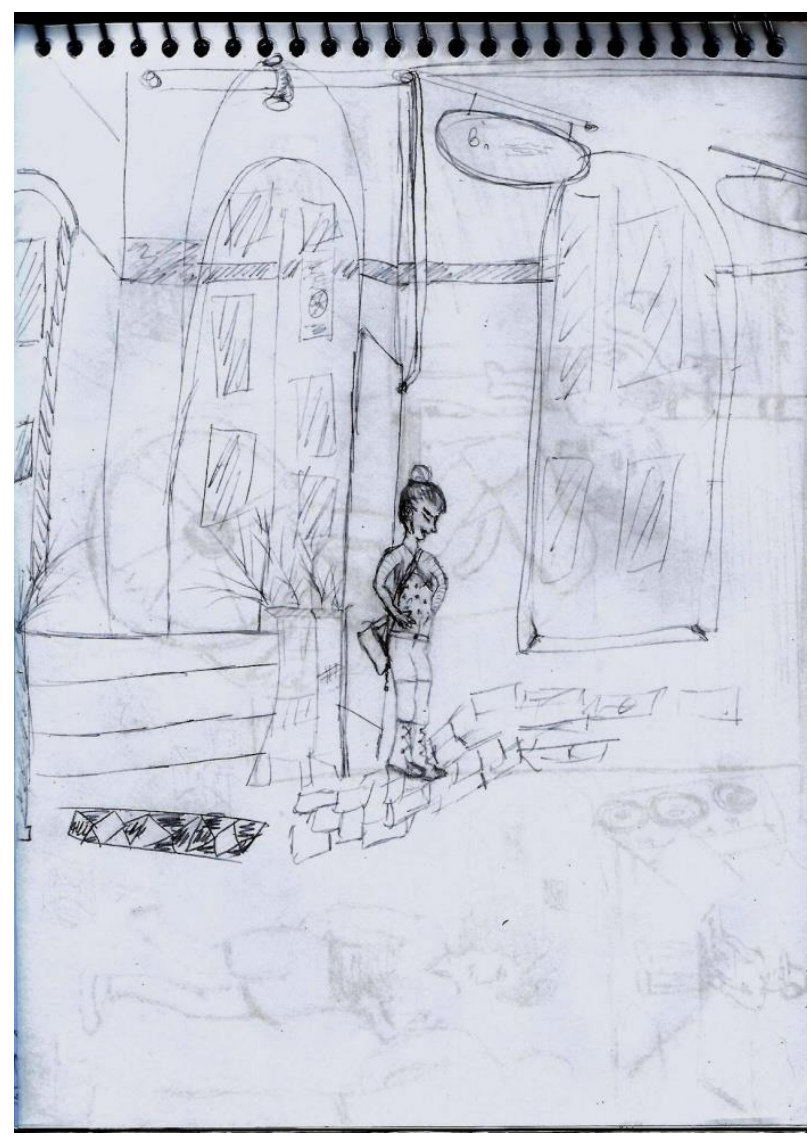

\section{Etnografia e deficiência visual: a cidade de quem não vê}

Em agosto de 2017 o autor desse artigo mergulha em campo, na Associação Escola Louis Braille, um complexo de três instituições que atende crianças, jovens e adultos de Pelotas e região. Nesse complexo, além de uma Escola de Ensino Fundamental para crianças com deficiência visual e uma instituição de Ensino de Jovens e Adultos, há o Centro de Reabilitação Visual (CRV), o qual recebe pessoas que já tiveram visão em algum momento da vida e hoje possuem baixa visão ou cegueira. $O$ interesse por essa Instituição vem por agregar pessoas que possuem experiência em adaptar seus corpos às novas condições necessárias para continuar habitando espaços e se deslocar por eles.

Durante negociação com a Instituição para a realização do trabalho, as coordenadoras propuseram ao autor a elaboração de trabalhos palpáveis, em formato de oficinas, para que fosse dinâmica a interação com o grupo. Isso garantiu uma intensa atuação no campo, pois o 
antropólogo pesquisador passou para a posição de o oficineiro do grupo ${ }^{4}$. Dentre as formas de registro da produção de dados em campo estão a fotografia, a escrita e a gravação de áudio. $\mathrm{O}$ desenho vem somente no momento pós campo, a partir da observação das imagens registradas.

Contudo, ao realizar o exercício de desenhar a partir de imagens feitas em campo, fica evidente a presença excessiva de uma materialidade acessória a essas pessoas: os óculos solares, a bengala e, por momentos, óculos de lentes espessas. A bengala serve como um sensor para desviar de obstáculos e desníveis. As lentes espessas são artifícios para ampliar a baixa visão. E os óculos solares, para alguns serve como proteção a visão de grau baixo ou ao órgão (o olho) que ainda está ali presente. Para outros, aparentemente, é mero critério estético.

Na rua, um cego não passa despercebido justamente pela sua bengala e, muitas vezes, seus óculos solares. Quando reunidos em grupo, como no CRV, é possível notar a utilização desses materiais pela maioria das pessoas. E, no caso dos óculos solares, para muitas pessoas não é evidente compreender o porquê da utilização. Essa é uma questão para retorno a campo e ouvir o que elas dizem.

Surge o pensamento, observando os inúmeros registros da presença dessa materialidade, que esses objetos estão para além de uma categoria acessória: são mais que uma extensão do corpo. Elas são o próprio corpo. A bengala tateando o chão ou obstáculos seria a própria mão da pessoa. As lentes espessas poderiam ser olhos gigantes de recepção de luz para envio da imagem à retina. E, os óculos solares, uma espécie de superproteção aos olhos e ao rosto, com possibilidade de personalização para efeitos estéticos.

Com esse corpo em condição de deficiência e cheio de novos formatos, garantido pela utilização desses acessórios, retorno a Mauss (1974) e suas técnicas de corpo. Caminhar, agora, não é mais movimentar em ritmo harmonioso a perna direita alternada pela perna esquerda. O braço, extenso por uma bengala, é acionado antes do próximo passo à frente, no intuito de efetivar a caminhada sem esbarrar em algum obstáculo ou cair em algum buraco. Uma técnica nova a ser apreendida e eficaz por sua repetição, visto que assim funciona com a maioria das pessoas com deficiência visual.

Para as pessoas com baixa visão, a espessura das lentes garante um alongamento dos olhos, aumentando o potencial de visão. Contudo, não basta simplesmente direcionar o rosto e focar no ponto a ser visto: o corpo inteiro deve se aproximar para realizar o foco da visão.

\footnotetext{
${ }^{4}$ Além do Trabalho de Conclusão de Curso referenciado nesse artigo, um resumo da proposta de campo pode ser lida em Rodrigues e Magni (2018).
} 
Angela é o exemplo disso quando ela comenta em como faz para buscar um endereço. Ela caminha bem próxima a fachada das residências para enxergar. Caso não encontre, ela precisa retornar ao ponto inicial da caminhada, trocar o lado da rua, e pesquisar novamente pelo seu destino.

Dadas as reflexões sobre o universo das pessoas com deficiência visual dessa pesquisa, há um desafio de como trazer as imagens dessas relações descobertas a partir do processo de desenhar. É o momento em que um tom surrealista incorpora dos traços de nanquim e aquarela do autor, buscando dar conta de mais detalhes dessa experiência etnográfica. A seguir, o conjunto de desenhos em narrativa desse processo de observar, desenhar descobrir.

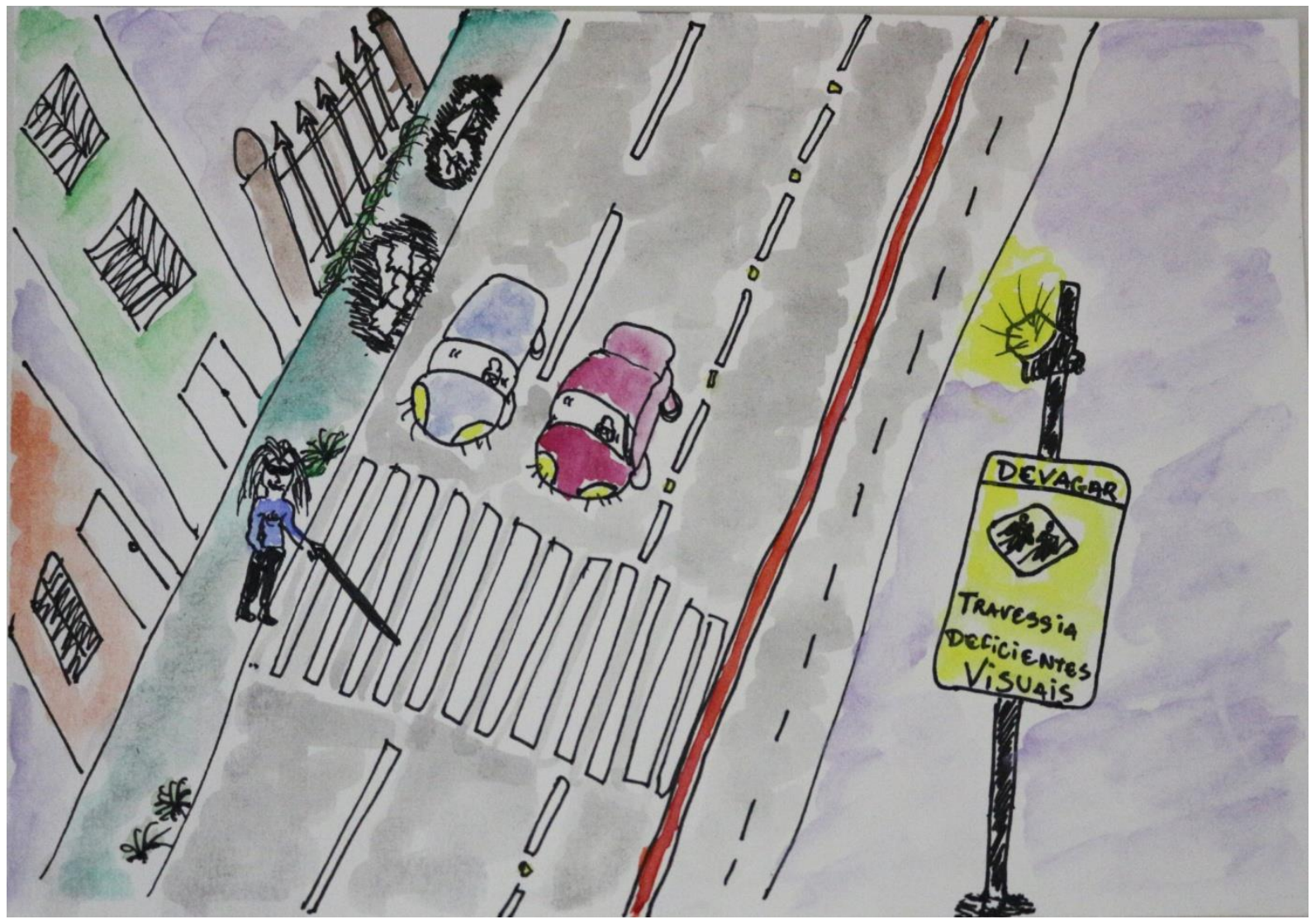


RELACult - Revista Latino-Americana de Estudos em Cultura e Sociedade

Revista Latinoamericana de Estudios en Cultura y Sociedad | Latin American Journal of Studies in Culture and Society V. 05, ed. especial, abr., 2019, artigo n ${ }^{\circ} 1381$ | claec.org/relacult |e-ISSN: 2525-7870

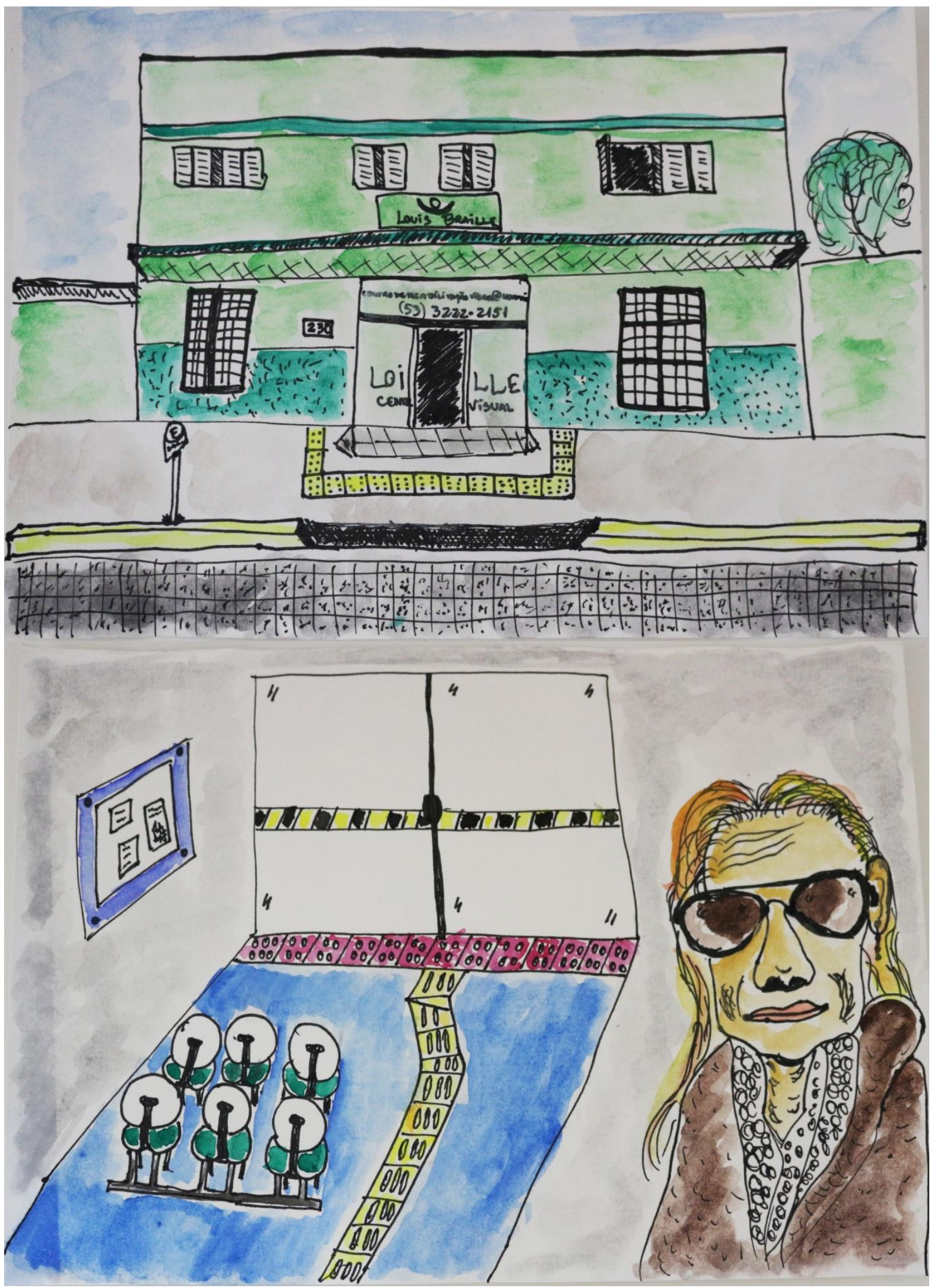


RELACult - Revista Latino-Americana de Estudos em Cultura e Sociedade

Revista Latinoamericana de Estudios en Cultura y Sociedad | Latin American Journal of Studies in Culture and Society V. 05, ed. especial, abr., 2019, artigo n ${ }^{\circ} 1381$ | claec.org/relacult |e-ISSN: 2525-7870

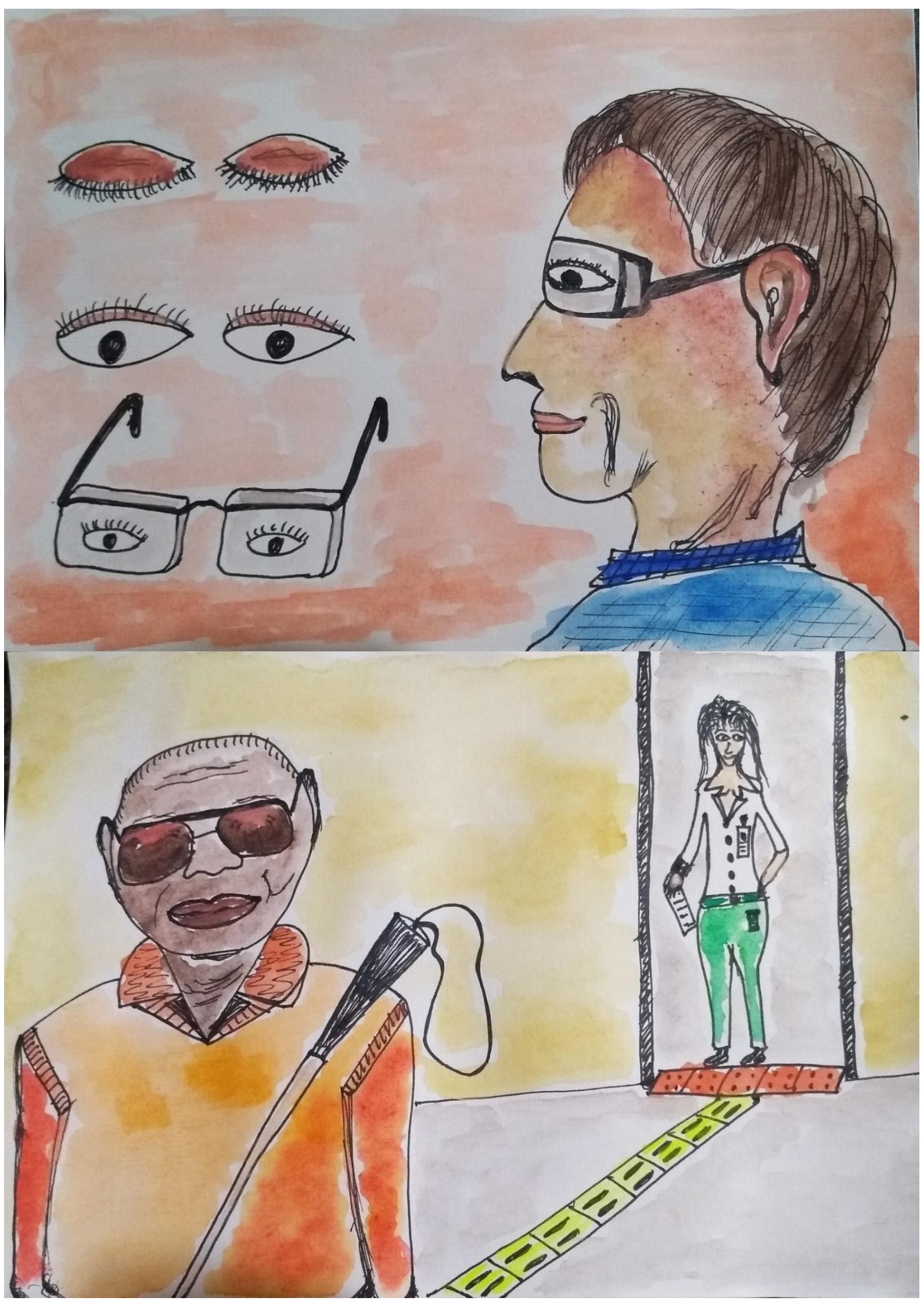


RELACult - Revista Latino-Americana de Estudos em Cultura e Sociedade

Revista Latinoamericana de Estudios en Cultura y Sociedad | Latin American Journal of Studies in Culture and Society

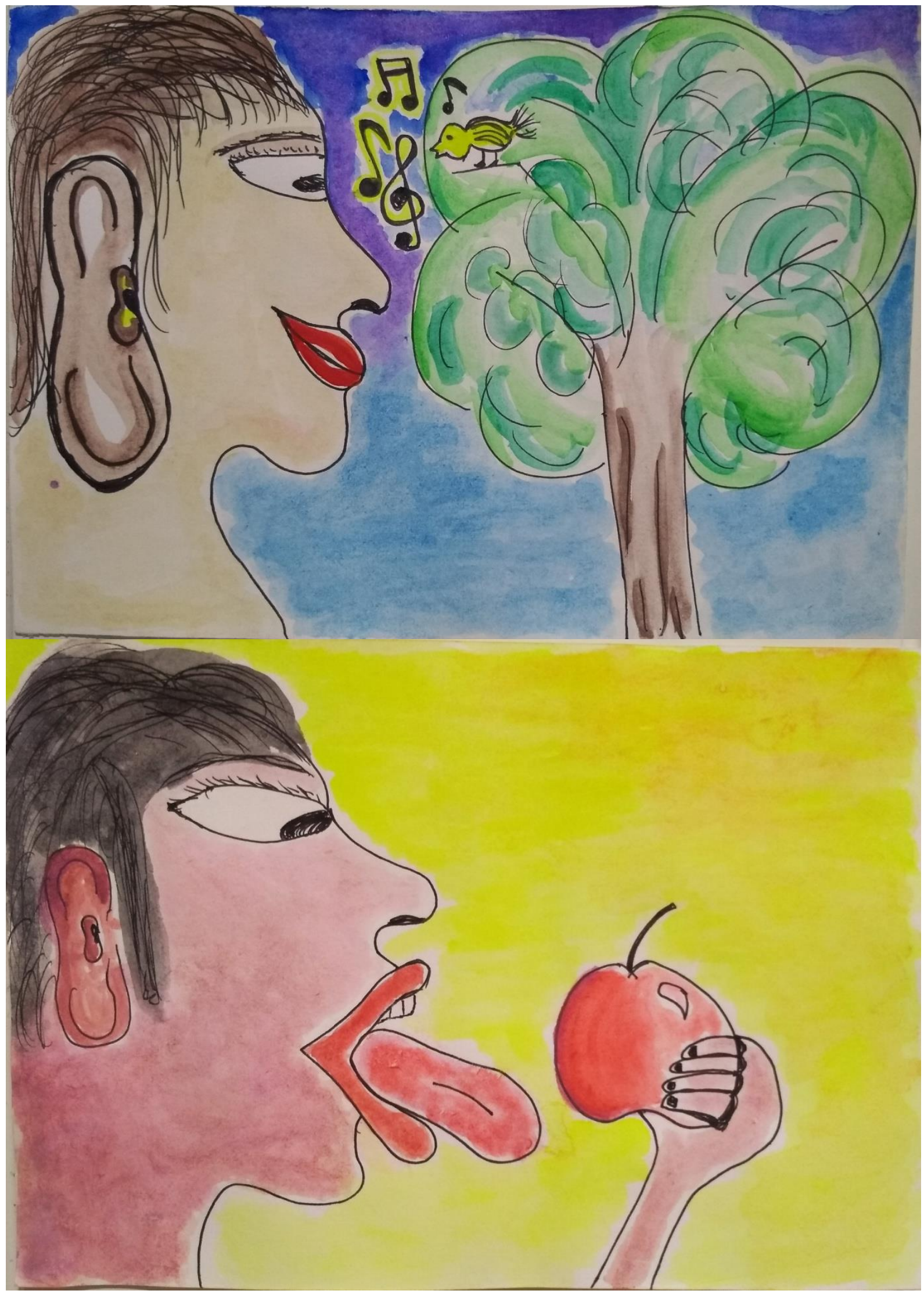


RELACult - Revista Latino-Americana de Estudos em Cultura e Sociedade

Revista Latinoamericana de Estudios en Cultura y Sociedad | Latin American Journal of Studies in Culture and Society V. 05, ed. especial, abr., 2019, artigo n ${ }^{\circ} 1381$ | claec.org/relacult |e-ISSN: 2525-7870

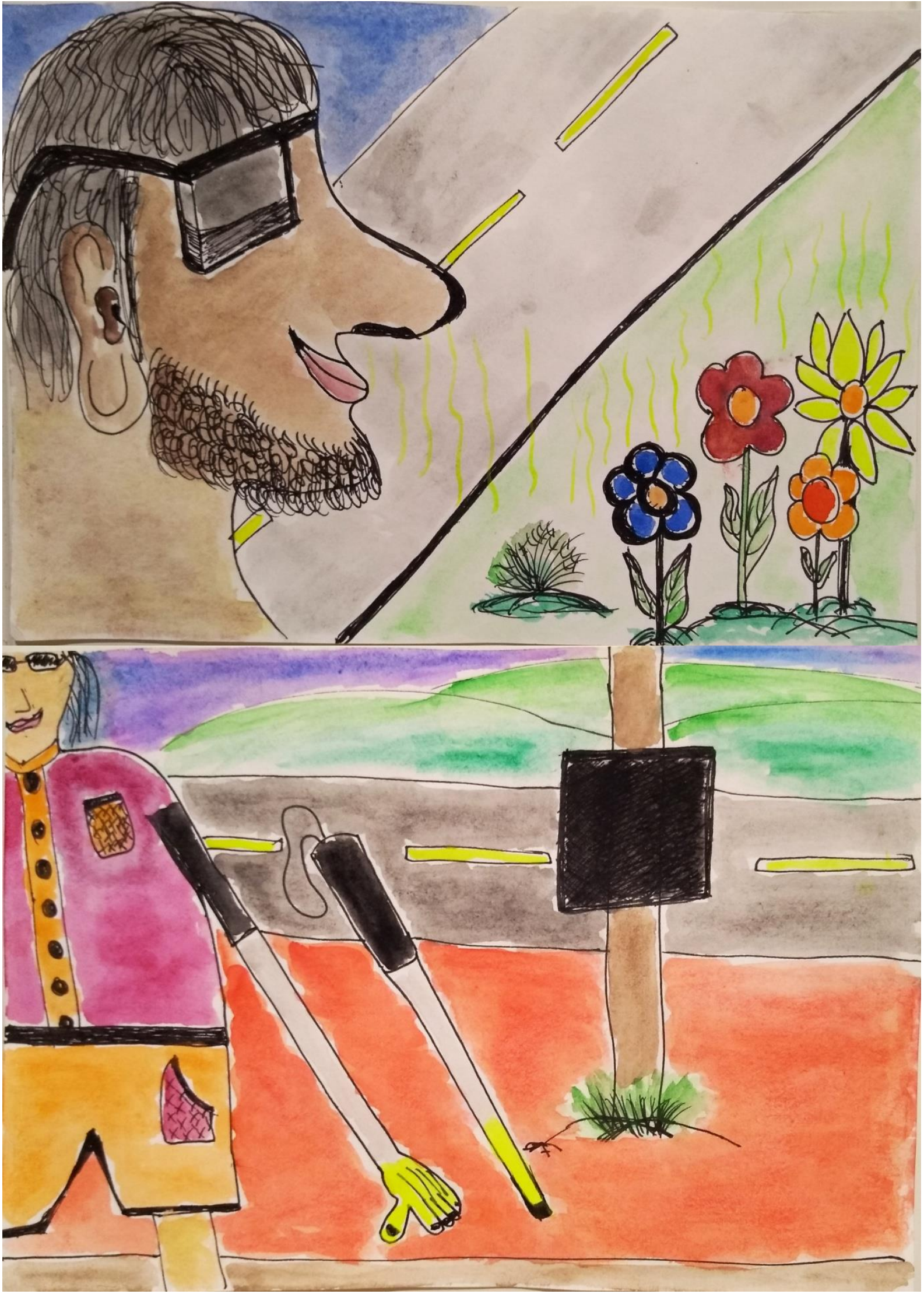




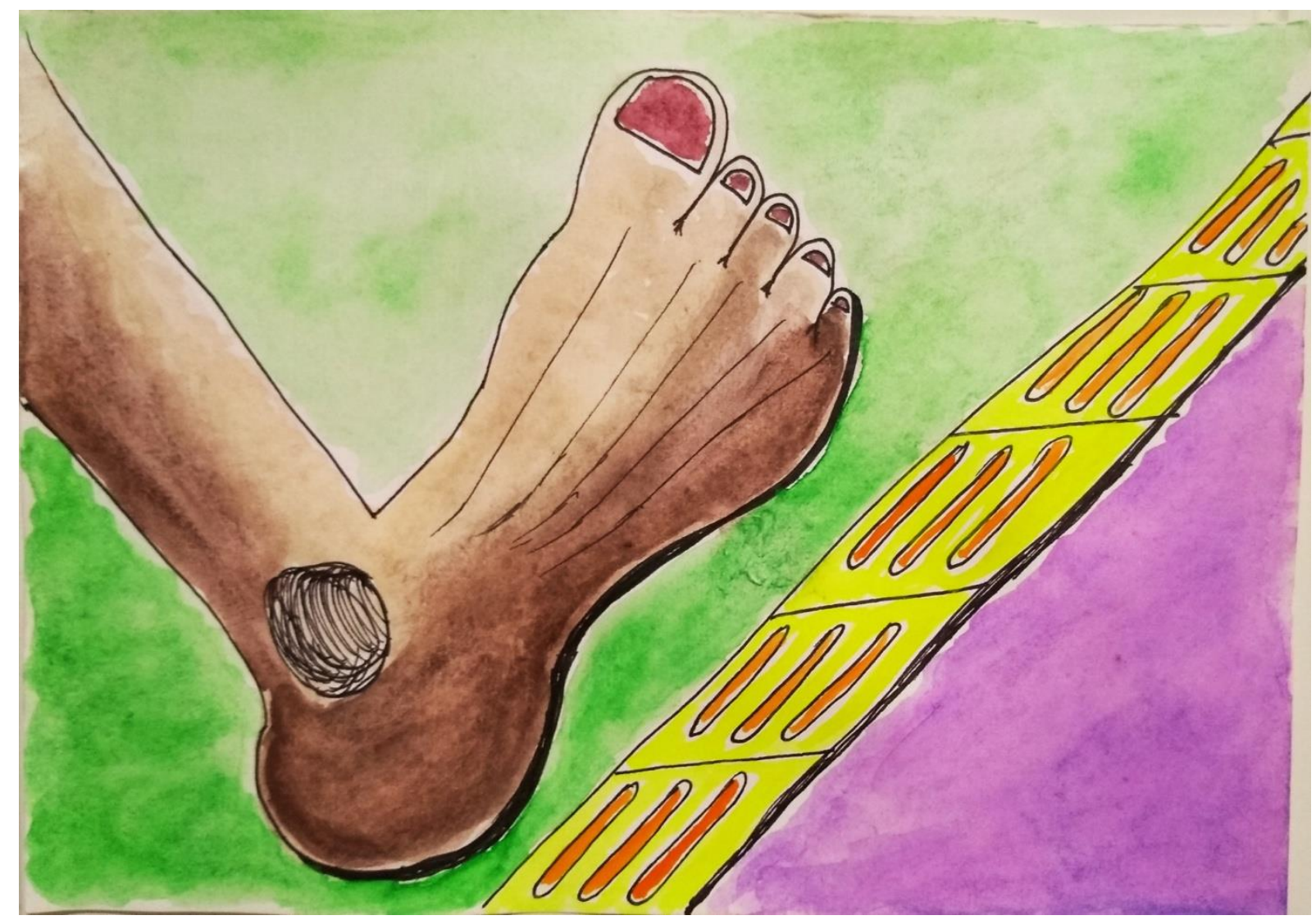

\section{Considerações finais}

O artigo que discorreu sobre o difícil momento de construção da etnografia para antropólogas e antropólogos na solidão da escrita, tema que parece não se esgotar nas discussões sobre "como apresentarmos" as pesquisas na área, realiza um movimento contrário ao que se teria como destino fatal da etnografia: a cópia de modelos tradicionais de escrita acadêmica. Isso torna frutífera a constante busca por novos meios de narrar nossas pesquisas, ou a insistência em enfrentar as resistências sobre as incertezas do desenho como ferramenta pertinente e, suficientemente madura de contemplar a arte poética do cotidiano e ciência no momento da escrita acadêmica antropológica e seus atravessamentos com outras áreas do conhecimento. A relação que se seguiu no processo de construção do produto etnográfico, a partir da utilização do desenho como forma de narrar além verbo, estabelece o amadurecimento de nossos diários de anotações, portanto, do etnógrafo em si, quando o desenho sai da esfera da relação íntima pesquisador/campo e se coloca na intimidade da relação com o leitor. 


\section{Referências}

AZEVEDO, A.. Diário de Campo e Diário Gráfico: contribuições do desenho à antropologia. Áltera - Revista de Antropologia, João Pessoa, v. 2, n. 2, p. 100-119, jan. / jun. 2016. Disponível em <http://periodicos.ufpb.br/index.php/altera/article/view/34737>. Acesso: jul. 2017.

AZEVEDO, A.. Desenho e Antropologia: Recuperação Histórica e Momento Atual. Rev. Cadernos de Arte e Antropologia, Vol.5, $\mathrm{n}^{\circ} .2$, p. 15-32; 2016. Disponível em $<$ https://journals.openedition.org/cadernosaa/1096?file=1>. Acesso: jan. 2019.

CUSTÓDIO, L. A.. Roteiros de arquitetura da Costa Doce: Rio Grande do Sul. Porto Alegre: Ed. Sebrae, 2009.

GARCIA, T.. Dinâmicas do patrimônio cultural: O caso do Mercado Público de Pelotas RS. In SANTOS. A.B.; MACHADO, J. P.; COLVERO, R. B.. Interdisciplinaridades

nas Ciências Humanas: Caminhos da pesquisa contemporânea. (Orgs.) (Livro eletrônico). Jaguarão: CLAEC, 1 ed., p. 1858-1873, 2017.

Disponível

em

<https://books.google.com.br/books?id=hTVCDwAAQBAJ\&lpg=PP1\&hl=pt-

$\mathrm{BR} \& \mathrm{pg}=\mathrm{PP} 1 \# \mathrm{v}=$ onepage $\& \mathrm{q} \& \mathrm{f}=$ false $>$. Acesso: dez. 2017.

GARCIA, T. Mercado Público de Pelotas no País das Maravilhas: uma etnografia sobre a pluralidade narrativa de um patrimônio em disputa. (Dissertação de Mestrado) Programa de

Pós-Graduação em Antropologia, UFPel. Pelotas, 201; 212p.

KUSCHNIR, K.. A antropologia pelo desenho: Experiências visuais e etnográficas. Cadernos de Arte e Antropologia, Vol. 5, n² 2, pag. 5-13, 2016.

MAUSS, Marcel. As técnicas do corpo. In:Sociologia e Antropologia, vol. II. São Paulo: Epu/Edusp, 1974.

NOVAES, S. C.. A antropologia Contemporânea - Temas de investigação, coleta de dados $e$ modelos teóricos: O diálogo entre a antropologia, a psicologia e a linguística. In Jogo de Espelhos: Imagens e representação de si através dos Outros.. Ed. USP, p. 47-60, São Paulo, 1993.

PEIRANO, Mariza. Etnografia não é método. Horizontes Antropológicos. Porto Alegre: v.

20, n. 42, p. 377-391, 2014. Disponível em: 〈http://www.scielo.br/pdf/ha/v20n42/15.pdf> Acesso: set. 2017

RODRIGUES, Guilherme R. de. Antropologia em ação: etnografia sobre o Centro de Reabilitação Visual Louis Braille em Pelotas-RS. Trabalho de Conclusão de Curso (Graduação em Antropologia - Antropologia Social e Cultural ou Arqueologia) — Instituto de Ciências Humanas, Universidade Federal de Pelotas, 2018.

RODRIGUES, G., MAGNI, C. Antropologia E Deficiência Visual: Pesquisa Etnográfica No Centro De Reabilitação Visual Louis Braille Em Pelotas-Rs. Caderno de resumos do XX Encontro de Pós-Graduação da UFPel. Disponível em: https://wp.ufpel.edu.br/enpos/. Acesso em: janeiro, 2017. 
RELACult - Revista Latino-Americana de Estudos em Cultura e Sociedade

Revista Latinoamericana de Estudios en Cultura y Sociedad | Latin American Journal of Studies in Culture and Society V. 05, ed. especial, abr., 2019, artigo no 1381 | claec.org/relacult | e-ISSN: 2525-7870

WAGNER, Roy. A invenção da Cultura. São Paulo: Cosac Naify, 2010. 